\title{
Black:White Health Disparities in the United States and Chicago: 1990-2010
}

\author{
Bijou Hunt • Steve Whitman
}

Received: 16 April 2014 /Revised: 24 July 2014 / Accepted: 22 August 2014 / Published online: 11 September 2014

(C) W. Montague Cobb-NMA Health Institute 2014

\begin{abstract}
Objectives In order to assess progress in eliminating health disparities, a Healthy People 2010 goal, both at the national level and in Chicago, Illinois, we examined whether disparities between non-Hispanic Black and non-Hispanic White persons widened, narrowed, or stayed the same between 1990 and 2010.

Methods We examined 17 health status indicators. In order to determine whether a disparity widened, narrowed, or remained unchanged between 1990 and 2010, we examined the relative percentage difference in rates at both time points and at each location. We calculated $P$ values to determine whether changes in relative percentage difference over time were statistically significant.

Results Disparities between non-Hispanic Black and nonHispanic White populations widened for 8 of the 17 health status indicators examined for the USA (6 significantly), whereas in Chicago the majority of disparities widened ( 9 of 17,4 significantly). The mortality gap is responsible for more than 60,000 excess Black deaths per year in the USA.

Conclusions Despite substantial effort and funds aimed at meeting the Healthy People 2010 goal of eliminating health disparities, minimal progress has been made.
\end{abstract}

Keywords Health disparities · Race/ethnicity $\cdot$ Mortality · Infectious disease

Steve Whitman is deceased.

B. Hunt $(\bowtie)$

Sinai Urban Health Institute, Room K443, Mount Sinai Hospital,

1500 S. California Ave, Chicago, IL 60608-1797, USA

e-mail: bijou.hunt@sinai.org

S. Whitman

Sinai Urban Health Institute, Room K437, Mount Sinai Hospital, 1500 S. California Ave, Chicago, IL 60608-1797, USA
Over the course of the past several decades, the topic of health disparities has garnered increasing attention in the US and, more recently, efforts to measure improvements therein have followed [1]. In 1985, the Report of the Secretary's Task Force on Black and Minority Health called for programs and policies to address health disparities [2]. This was followed by increasingly aggressive Healthy People goals in 1990 to reduce health disparities by 2000 [3], in 2000 to eliminate health disparities by 2010 [4], and in 2010 to achieve health equity and improve the health of all groups of people in the USA by 2020 [5].

Although it has been common to examine whether disparities (e.g., Black:White or SES disparities) have improved over time for a given metric (e.g., diabetes prevalence or cardiovascular mortality), it has been rather rare to look at a collection of health status indicators (HSIs) over time to try to assess general progress. Some studies, however, have pursued this analytic path. A 2001 study by Silva et al. examined 22 health status indicators for Black and White people in Chicago between the years 1990 and 1998 [6]. In 2002, Keppel et al. presented national data for 17 health status indicators for the five largest race/ethnic groups in the USA for the years 1990 and 1998 and found that for the majority of indicators, disparities declined [7]. A comparable analysis by Margellos et al. focused on non-Hispanic Black:non-Hispanic White differences in Chicago for the same period and found that while disparities were decreasing nationally, in Chicago, the majority of indicators actually widened over the interval [8]. Most recently, Orsi et al. examined 15 health status indicators for non-Hispanic Blacks and non-Hispanic Whites in both Chicago and the USA between 1990 and 2005. The authors found no significant trend toward overall improvement in health disparities for the USA with only about half of the indicators showing improvement. In Chicago, 11 of the 15 measures widened and 5 significantly so. The remaining four narrowed, but only two significantly so [9]. 
The present analysis seeks to provide an updated progress report of these same health status indicators for non-Hispanic Blacks and non-Hispanic Whites in Chicago and the USA, for the 20-year interval between 1990 and 2010. This update provides a report of our status as a nation and also gives us a benchmark against which to measure Chicago's progress. In addition, we calculate the number of excess Black deaths due to disparities and find these figures to be alarmingly large.

\section{Methods}

Table 1 presents the 17 health status indicators included in the analysis, 14 of which were included in the previous analysis by Orsi et al. [9]. Three new indicators have been added here: HIV mortality and colon and prostate cancer mortality. One indicator has been removed from the analysis: first trimester prenatal care was not included due to revisions to the birth certificate and changes in the number of states reporting. We calculated all 17 health status indicators for the non-Hispanic Black and non-Hispanic White populations for both Chicago and the USA for the years 1990 and 2010. To determine whether disparities are improving or worsening, we compared the percent differences between the Black and White scores in 1990 and then in 2010.

Table 1 Health Status Indicators Included in the Analysis of BlackWhite Health Disparities: US and Chicago, IL, 1990 and 2010
Excess deaths due to the racial disparity in all-cause mortality are calculated by multiplying the age-specific White mortality rates by the corresponding Black populations in each age category. The sum of these products is the number of Black deaths that would be expected if White death rates were applied to this population. We then subtracted the number of expected deaths from the number of observed deaths to obtain the excess number of deaths for both Chicago and the US [10].

\section{Measures Employed}

The 13 indicators of mortality are age-adjusted using the 2000 US population as the standard. This is the age distribution currently employed by the National Center for Health Statistics (NCHS) in its National Vital Statistics Reports [11, 12]; thus, the US data presented here can be easily compared to and checked against the data available from NCHS in its published reports. Age-adjusted rates are expressed per 100,000 population (or per 100,000 women for female breast cancer or per 100,000 men for prostate cancer). Because 1990 causespecific mortality data were generated with International Classification of Diseases, Ninth Revision (ICD-9) codes [13] and 2010 data were generated with ICD, Tenth Revision codes [14] (ICD-10), we used an age-specific comparability

\begin{tabular}{|c|c|c|}
\hline Health status indicators & ICD-9 codes & ICD-10 codes \\
\hline \multicolumn{3}{|l|}{ Mortality rates } \\
\hline Heart disease & $390-398,402,404-429$ & I00-I09, I11, I13, I20-I51 \\
\hline Cancer & $140-208$ & $\mathrm{C} 00-\mathrm{C} 97$ \\
\hline Female breast cancer & 174 & $\mathrm{C} 50$ \\
\hline Colorectal cancer & 153,154 & $\mathrm{C} 18-\mathrm{C} 21$ \\
\hline Lung cancer & 162 & $\mathrm{C} 33-\mathrm{C} 34$ \\
\hline Prostate cancer & 185 & C61 \\
\hline Stroke & $430-438$ & I60-I69 \\
\hline Motor vehicle accidents & E810-E825 & $\begin{array}{l}\text { V09.9,V09.2,V12-V14,V19.0-V19.2, } \\
\text { V19.4-V19.6,V20-V79, V80.3-V80.5, } \\
\text { V81.0-81.1,V82.0-V82.1,V83-V86, } \\
\text { V87.0-V87.8, V88.0-V88.8, V89.0,V89.2 }\end{array}$ \\
\hline Diabetes mellitus & 250 & E10-E14 \\
\hline Homicide & E960-E978 & X85-Y09, Y87.1 \\
\hline Suicide & E950-E959 & U03,X60-X84,Y87.0 \\
\hline $\begin{array}{l}\text { Human Immunodeficiency } \\
\text { virus (HIV) disease } \\
\text { All cause }\end{array}$ & $042-044$ & B20-B24 \\
\hline \multicolumn{3}{|l|}{ Birth-related outcomes } \\
\hline \multicolumn{3}{|l|}{ Infant mortality rate } \\
\hline \multicolumn{3}{|l|}{$\begin{array}{l}\text { Percentage low-birthweight } \\
\text { babies }\end{array}$} \\
\hline \multicolumn{3}{|l|}{ Communicable disease incidence } \\
\hline \multicolumn{3}{|l|}{ Tuberculosis } \\
\hline Primary and secondary syphilis & & \\
\hline
\end{tabular}


ratio formula designed specifically for transforming ageadjusted rates from the $I C D-9$ to $I C D-10$ coding so that the 1990 and 2010 rates were comparable [15]. The infant mortality rate is expressed as the number of deaths among infants (in the first year of life) per 1,000 live births. US infant mortality rates are calculated with linked birth-death files. Because this source was not available for Chicago, we calculated this rate by dividing the number of infant deaths in a given year by the number of live births in that same year. Lowbirthweight $(<2,500 \mathrm{~g})$ is expressed as a percentage and is restricted to the population for which data regarding birthweight status was known. The two communicable disease incidence rates, for tuberculosis and primary and secondary syphilis, were calculated per 100,000 population (unadjusted for age).

\section{Chicago Data}

Communicable disease data were provided by the Chicago Department of Public Health (CDPH) Tuberculosis Control Program (tuberculosis counts) and Division of STD/HIV/ AIDS (syphilis counts). Tuberculosis and syphilis are diseases notifiable by state law, meaning providers are required to report any case to $\mathrm{CDPH}$, which then reviews the case and determines if it is new. Chicago numerators for 1990 were abstracted from the vital records (birth and death files) maintained by the Illinois Department of Public Health [16]. Chicago numerators for 2010 were abstracted from birth and death files obtained from the National Center for Health Statistics [17]. Population-based denominators for Chicago in 1990 and 2010 were derived from the US Census.

\section{National Data}

Numerator data for the USA for 1990 and 2010 were abstracted from birth and death files obtained from the National Center for Health Statistics and through published reports [17]. The source of the mortality numerator data for the USA for 1990 for this analysis differs from the source used by Orsi et al. [9]. The previous analysis by Orsi employed data obtained through a special request from NCHS, while we obtained the file directly and abstracted the data ourselves. We believe these updated data are more accurate than what was previously available to Orsi. Population-based denominators for 1990 and 2010 were derived from the US Census data.

\section{Analysis of Trends}

To measure the disparity, we calculated the relative percentage difference (percentage difference) between the non-Hispanic Black (Black) and non-Hispanic White (White) rates for 1990 and 2010. The formula for calculating the relative percentage difference is

$\left(R_{\mathrm{i}}-R_{\mathrm{r}}\right) / R_{\mathrm{r}} \times 100$

where $R_{\mathrm{i}}$ is the rate for the index group, in this case Black, and $R_{\mathrm{r}}$ is the rate for the reference group, in this case White [18]. The sign of the percentage difference is positive if the Black rate is higher than the White rate and negative if the White rate is higher than the Black rate. The disparity is widening if the percentage difference is getting larger and narrowing if the percentage difference is getting smaller (regardless of sign). One exception is in the case of suicide mortality where the disparity is considered to be widening if it gets increasingly negative.

\section{Statistical Analyses}

To determine whether a disparity widened or narrowed significantly between 1990 and 2010, we calculated a two-sided $z$ score by using a bootstrap technique developed by Keppel et al. [18] and examined the corresponding $P$ value for the $z$ score. A $P$ value of less than 0.05 was considered significant for all analyses. It should be noted here that despite the fact that mortality and natality data are not subject to sampling error, standard errors were calculated to account for any unknown random variation. This is in line with the approach employed by the Centers for Disease Control, in which estimates of nonsampling error are calculated for rates based on vital statistics data [7, p. 14].

\section{Results}

Table 2 presents results for the USA. In both 1990 and 2010, the non-Hispanic Black (Black) rate for nearly all health status indicators (HSI) was higher than the nonHispanic White (White) rate. The one exception was suicide mortality at both time points. Improvements were made for Black people between 1990 and 2010 for every HSI with the exception of the percentage of low birthweight babies (which increased only slightly from 13.3 to 13.5 ). For White people, improvements were made for all HSIs except suicide mortality (which increased from 13.8 to 15.2) and the percentage of low birthweight babies (which increased from 5.6 to 7.1 ).

Between 1990 and 2010, the Black-White disparities narrowed for 9 of the 17 HSIs. Eight of the nine significantly narrowed (all-cause mortality, all cancer mortality, lung cancer mortality, motor vehicle crash mortality, homicide mortality, percentage low birthweight babies, and tuberculosis and 
Table 2 Health status indicators and rates by race, year, and associated Black-White percentage differences: USA, 1990 and 2010

\begin{tabular}{llll}
\hline Indicator & Non- & Non- & Difference, $P$ \\
& Hispanic & Hispanic $\%$ \\
& Black & White & \\
& rate & rate &
\end{tabular}

\begin{tabular}{|c|c|c|c|c|c|c|c|c|c|}
\hline \multicolumn{5}{|l|}{ Black-White percentage } & \multirow{5}{*}{ Indicator } & \multirow{5}{*}{$\begin{array}{l}\text { Non- } \\
\text { Hispanic } \\
\text { Black } \\
\text { rate }\end{array}$} & \multirow{5}{*}{$\begin{array}{l}\text { Non- } \\
\text { Hispanic } \\
\text { White } \\
\text { rate }\end{array}$} & \multirow{5}{*}{$\begin{array}{l}\text { Difference, } \\
\%\end{array}$} & \multirow{5}{*}{$P$} \\
\hline \multirow{5}{*}{ Indicator } & \multirow{5}{*}{$\begin{array}{l}\text { Non- } \\
\text { Hispanic } \\
\text { Black } \\
\text { rate }\end{array}$} & \multirow{5}{*}{$\begin{array}{l}\text { Non- } \\
\text { Hispanic } \\
\text { White } \\
\text { rate }\end{array}$} & & \multirow{4}{*}{$P$} & & & & & \\
\hline & & & \multirow{4}{*}{$\begin{array}{l}\text { Difference, } \\
\%\end{array}$} & & & & & & \\
\hline & & & & & & & & & \\
\hline & & & & & & & & & \\
\hline & & & & & 2010 & 13.5 & 7.1 & 90.1 & \\
\hline \multicolumn{4}{|l|}{ All-cause mortality ${ }^{\mathrm{a}}$} & \multirow[t]{3}{*}{$<0.0001$} & Tuberculosis case rate $\mathrm{f}^{\mathrm{f}}$ & & & & \multirow[t]{3}{*}{$<0.000$} \\
\hline 1990 & $1,263.3$ & 911.3 & 38.6 & & 1990 & 33.0 & 4.2 & 685.7 & \\
\hline 2010 & 939.8 & 759.9 & 23.7 & & 2010 & 7.0 & 0.9 & 677.8 & \\
\hline \multicolumn{4}{|l|}{ Heart disease mortality ${ }^{\mathrm{a}}$} & \multirow[t]{3}{*}{$<0.0001$} & \multirow{3}{*}{$\begin{array}{l}\text { Primary and secondary } \\
\text { syphilis case rate } \\
1990\end{array}$} & & & & \multirow[t]{3}{*}{$<0.0001$} \\
\hline 1990 & 383.0 & 314.3 & 21.9 & & & & & & \\
\hline 2010 & 233.0 & 180.8 & 28.9 & & & 142.5 & 2.6 & $5,380.8$ & \\
\hline Stroke mortality & & & & 0.48 & 2010 & 17.3 & 2.2 & 686.4 & \\
\hline
\end{tabular}

1990

2010

Cancer mortality $^{\mathrm{a}}$

1990

2010

$96.4 \quad 66.0$

46.1

$55.1 \quad 38.0$

45.0

$284.4 \quad 216.2 \quad 31.5$

Colorectal cancer mortality

1990

2010

Lung cancer mortality ${ }^{\mathrm{a}}$

1990

2010

Female breast cancer mortality $^{\mathrm{b}}$

1990

2010

Prostate cancer mortality ${ }^{\mathrm{c}}$

1990

2010

Diabetes mellitus mortality 1990

2010

Motor vehicle crash

mortality ${ }^{\mathrm{a}}$

1990

2010

Suicide mortality ${ }^{\mathrm{a}}$

1990

2010

Homicide mortality ${ }^{\mathrm{a}}$

1990

2010

HIV mortality ${ }^{\mathrm{a}}$

1990

2010

Infant mortality rate ${ }^{\mathrm{d}}$ $1990^{\mathrm{e}}$

2010

$\%$ Low-birthweight babies ${ }^{\mathrm{e}}$ 1990
$210.8 \quad 177.6$

$30.1 \quad 24.0$

$22.6 \quad 15.6$

$\begin{array}{ll}72.0 & 59.2\end{array}$

$52.7 \quad 51.1$

38.6

$31.9 \quad 22.3$

75.3

49.7

35.2

20.4

40.9

40.3

18.7

18.3

18.7

12.2

17.5

12.1

6.9

0.8

$\begin{array}{lll}7.3 & 13.8 & -47.1\end{array}$

$\begin{array}{lll}5.9 & 15.2 & -61.2\end{array}$

$37.8 \quad 4.3$

779.1

$\begin{array}{lll}20.4 & 2.6 & 684.6\end{array}$

27.0

12.8

7.5

260.0

$1.1 \quad 1,063.6$

$\begin{array}{lll}16.9 & 7.2 & 134.7\end{array}$

$12.0 \quad 5.1 \quad 135.3$

$\begin{array}{lll}13.3 & 5.6 & 137.5\end{array}$
Table 2 (continued)

1990 cause-specific mortality rates are modified by a comparability ratio to be comparable to 2010 rates. Percentage difference is a relative difference calculated using the formula ((Black rate-White rate)/(White rate) $) \times 100$

${ }^{a}$ Age-adjusted and expressed per 100,000 population

${ }^{\mathrm{b}}$ Age-adjusted and expressed per 100,000 women

${ }^{\mathrm{c}}$ Age-adjusted and expressed per 100,000 men

${ }^{d}$ Number of deaths among infants (in the first year of life) per 1,000 live births

${ }^{\mathrm{e}}$ Forty-eight states and DC only. Hispanic origin was not reported in 1990 by New Hampshire and Oklahoma

${ }^{\mathrm{f}}$ Per 100,000 population

$<0.0001$

primary and secondary syphilis case rate). During the same time period, the disparities widened for 8 of the 17 HSIs, 6 significantly (heart disease mortality, colorectal, female breast, and prostate cancer mortality, suicide mortality, and HIV mortality). Although the disparity in the suicide mortality rates did widen significantly, this was because the White rate increased, while the Black rate decreased. The Black-White disparity in infant mortality remained virtually unchanged, though rates for both groups improved slightly over the period.

Table 3 presents results for Chicago. In both 1990 and 2010, the Black rate for nearly all HSIs was higher than the

$<0.0001$ White rate. The exceptions were suicide mortality at both time points and HIV mortality in 1990. Improvements were made for Black people between 1990 and 2010 for every HSI. For White people, improvements were made for all HSIs with the exception of the percentage of low birthweight babies (which increased from 6.4 to 7.3 ) and the primary and secondary syphilis case rate which increased dramatically (by $296 \%$ ).

Between 1990 and 2010, the Black-White disparities narrowed for 8 of the 17 HSIs, 3 significantly so (the percentage of low birthweight babies, and tuberculosis and primary and secondary syphilis case rate). During the same period, the disparities widened for 9 of the 17 HSIs. Four of the nine significantly widened (heart disease mortality, motor vehicle crash mortality, homicide mortality and HIV mortality). 
Table 3 Health status indicators and rates by race, year, and associated Black-White percentage differences: Chicago, IL, 1990 and 2010

\begin{tabular}{|c|c|c|c|c|}
\hline Indicator & $\begin{array}{l}\text { Non- } \\
\text { Hispanic } \\
\text { Black rate }\end{array}$ & $\begin{array}{l}\text { Non- } \\
\text { Hispanic } \\
\text { White rate }\end{array}$ & $\begin{array}{l}\text { Difference, } \\
\%\end{array}$ & $P$ \\
\hline All-cause mortality ${ }^{\mathrm{a}}$ & & & & 0.38 \\
\hline 1990 & $1,429.0$ & $1,053.9$ & 35.6 & \\
\hline 2010 & $1,017.7$ & 738.9 & 37.7 & \\
\hline Heart disease mortality ${ }^{a}$ & & & & $<0.0001$ \\
\hline 1990 & 420.0 & 387.3 & 8.4 & \\
\hline 2010 & 272.4 & 213.7 & 27.5 & \\
\hline Stroke mortality ${ }^{\mathrm{a}}$ & & & & 0.42 \\
\hline 1990 & 81.5 & 60.1 & 35.6 & \\
\hline 2010 & 48.7 & 33.6 & 44.9 & \\
\hline Cancer mortality $^{\mathrm{a}}$ & & & & 0.56 \\
\hline 1990 & 324.6 & 244.9 & 32.5 & \\
\hline 2010 & 242.4 & 187.1 & 29.6 & \\
\hline $\begin{array}{l}\text { Colorectal cancer } \\
\text { mortality }^{\mathrm{a}}\end{array}$ & & & & 0.67 \\
\hline 1990 & 38.2 & 31.2 & 22.4 & \\
\hline 2010 & 24.6 & 21.1 & 16.6 & \\
\hline Lung cancer mortality ${ }^{\mathrm{a}}$ & & & & 0.18 \\
\hline 1990 & 83.4 & 61.6 & 35.4 & \\
\hline 2010 & 63.3 & 51.7 & 22.4 & \\
\hline $\begin{array}{l}\text { Female breast cancer } \\
\text { mortality }\end{array}$ & & & & 0.10 \\
\hline 1990 & 44.2 & 37.0 & 19.5 & \\
\hline 2010 & 36.2 & 24.2 & 49.6 & \\
\hline $\begin{array}{l}\text { Prostate cancer } \\
\text { mortality }\end{array}$ & & & & 0.25 \\
\hline 1990 & 82.1 & 35.2 & 133.2 & \\
\hline 2010 & 58.9 & 21.3 & 176.5 & \\
\hline $\begin{array}{l}\text { Diabetes mellitus } \\
\text { mortality }^{\mathrm{a}}\end{array}$ & & & & 0.69 \\
\hline 1990 & 39.4 & 22.2 & 77.5 & \\
\hline 2010 & 31.6 & 18.6 & 69.9 & \\
\hline $\begin{array}{l}\text { Motor vehicle crash } \\
\text { mortality }^{\mathrm{a}}\end{array}$ & & & & $<0.05$ \\
\hline 1990 & 16.0 & 14.3 & 11.9 & \\
\hline 2010 & 8.6 & 4.4 & 95.5 & \\
\hline Suicide mortality ${ }^{\mathrm{a}}$ & & & & 0.27 \\
\hline 1990 & 7.8 & 14.4 & -45.8 & \\
\hline 2010 & 3.8 & 10.9 & -65.1 & \\
\hline Homicide mortality ${ }^{\mathrm{a}}$ & & & & $<0.05$ \\
\hline 1990 & 58.4 & 7.0 & 734.3 & \\
\hline 2010 & 39.3 & 2.5 & $1,472.0$ & \\
\hline HIV mortality ${ }^{\mathrm{a}}$ & & & & $<0.0001$ \\
\hline 1990 & 25.8 & 26.0 & -0.8 & \\
\hline 2010 & 16.3 & 3.8 & 328.9 & \\
\hline Infant mortality rate ${ }^{\mathrm{d}}$ & & & & 0.16 \\
\hline 1990 & 23.1 & 7.5 & 208.0 & \\
\hline 2010 & 11.3 & 4.5 & 151.1 & \\
\hline $\begin{array}{l}\text { \% Low-birthweight } \\
\text { babies }\end{array}$ & & & & $<0.0001$ \\
\hline 1990 & 15.4 & 6.4 & 140.6 & \\
\hline 2010 & 14.1 & 7.3 & 93.2 & \\
\hline
\end{tabular}

Table 3 (continued)

\begin{tabular}{lllll}
\hline Indicator & $\begin{array}{l}\text { Non- } \\
\text { Hispanic } \\
\text { Black rate }\end{array}$ & $\begin{array}{l}\text { Non- } \\
\text { Hispanic } \\
\text { White rate }\end{array}$ & $\begin{array}{l}\text { Difference, } \\
\%\end{array}$ & $P$ \\
\hline Tuberculosis case rate $^{\mathrm{e}}$ & & & & $<0.0001$ \\
$\quad 3590$ & 7.1 & 2.2 & 222.7 & \\
2010 & & & & $<0.0001$ \\
$\begin{array}{l}\text { Primary and secondary } \\
\text { syphilis case rate }\end{array}$ & 133.1 & 4.5 & 2857.8 & \\
1990 & 46.1 & 17.8 & 159.0 & \\
2010 & & & &
\end{tabular}

1990 cause-specific mortality rates are modified by a comparability ratio to be comparable to 2010 rates. Percentage difference is a relative difference calculated using the formula ((Black rate-White rate)/(White rate) $) \times 100$

${ }^{\text {a }}$ Age-adjusted and expressed per 100,000 population

${ }^{\mathrm{b}}$ Age-adjusted and expressed per 100,000 women

${ }^{\mathrm{c}}$ Age-adjusted and expressed per 100,000 men

${ }^{\mathrm{d}}$ Number of deaths among infants (in the first year of life) per 1,000 live births

${ }^{\mathrm{e}}$ Per 100,000 population

\section{Excess Black Deaths}

Table 4 presents the annual excess Black deaths for Chicago and the USA for the year 2010, as well as the percentage of Black deaths which are excess deaths. In 2010, there were 60,923 excess Black deaths in the US and 2,454 excess Black deaths in Chicago. In total, $21 \%$ of all US Black deaths were excess. That is, they would not have occurred if Black people in the USA had the same death rate as White people. For Chicago, that proportion was even higher at $28 \%$. Breaking this down to a daily death toll, we find that there are 167 excess Black deaths per day in the USA and 7 excess Black deaths per day in Chicago.

\section{Discussion}

Throughout the past several decades, the USA has placed increasing focus on the elimination of health disparities [1]. Attempts to establish whether progress is being made on this front have commonly included the examination of selected health metrics, but less commonly assess progress by

Table 4 Excess Black deaths and percentage of Black deaths that are excess: USA and Chicago, 2010

\begin{tabular}{lll}
\hline & Excess deaths & Percentage of deaths that are excess \\
\hline USA & 60,923 & $21 \%$ \\
Chicago & 2,454 & $28 \%$ \\
\hline
\end{tabular}


examining several metrics simultaneously. One particular area of concern is disparities among different racial and ethnic groups. We thus chose this area for analysis and examined racial disparities for 17 health status indicators (HSIs) for the non-Hispanic White and non-Hispanic Black populations in Chicago and the USA in 1990 and 2010. Fourteen of these measured mortality, one measured birth outcomes (other than infant mortality), and two measured infectious diseases.

For the USA, we found that the racial disparity (measured by the percentage difference) narrowed significantly for 8 of the 17 HSIs over the 20 -year period, while 1 other indicator improved but not significantly. Thus, slightly more than half of the health status indicators moved toward equality over the interval. At the same time, the disparities in eight indicators widened and six significantly so.

The situation in Chicago was far worse than for the USA. Of the 17 health status indicators examined, 8 narrowed, but only 3 significantly so. Conversely, nine indicators widened and four significantly so. What this looks like for individual HSIs is sobering. In 1990, the Black all-cause mortality rate was $35.6 \%$ higher than the White rate. Twenty years later, the disparity had not decreased at all and was $37.7 \%$. Equally alarming is the fact that some of these disparities actually appear to have grown between 2005 and 2010. For instance, as reported by Orsi et al., the percentage difference in Black:White heart disease mortality in 2005 was 24.3; this increased to 27.5 by 2010 [9]. The same widening is observed for diabetes mortality, where the percentage difference grew from 67.0 in 2005 to 69.9 in 2010. A similar pattern is observed for motor vehicle crash and homicide mortality. Thus, not only have we observed a widening of disparities between 1990 and 2010, we also see that even in the very recent past (2005 to 2010), disparities have been continuing to widen for several health status indicators.

One mortality measure of note is the infant mortality rate (IMR). In the USA, the disparity was $135 \%$ in 2010 , precisely the same that it was 20 years earlier. In 2010, the Black IMR was 12.0 (infant deaths per 1,000 live births). In Chicago, the disparity shrank from $208 \%$ in 1990 to $151 \%$ in 2010. Despite this improvement, the Black IMR in Chicago was 11.3 in 2010. This rate is higher than the overall rate for 56 countries in the world, including for example Cuba, Slovenia, and Bulgaria [19].

The other birth outcome measure included here, the percentage of low birthweight babies, decreased significantly in both Chicago and the USA, but the disparity was still close to $100 \%$ in 2010 . The decreasing disparity for low birthweight was particularly interesting. In the USA, the rates for both Blacks and Whites grew worse over the 20-year interval; however, since the White rate worsened more than the Black rate, the disparity actually declined. In Chicago, the Black rate improved slightly over the period, while the White rate worsened slightly, thus leading to a decline in the disparity.
We also analyzed two measures of infectious diseases, tuberculosis, and syphilis. In both the US and Chicago, the disparity for tuberculosis decreased a small but significant amount while the disparity for syphilis decreased a great deal but was still close to $700 \%$ in the US in 2010 .

We also calculated the number of excess Black deaths attributable to the Black:White mortality disparity. Though not commonly reported, this metric provides a simple and easy-to-understand number which quantifies the effect of the mortality gap. According to an article by Satcher and his colleagues, in 2002, there were 83,570 excess African American deaths in the USA [20]. The present analysis estimates that the number of excess Black deaths in the USA in 2010 was 60,923 . While this is a substantial improvement, this is still $21 \%$ of all Black deaths. In Chicago in 2010, there were 2,454 excess Black deaths, accounting for $28 \%$ of the total. This means that on an average day in Chicago in 2010, almost seven Black people died because the Black death rate was so much higher than the White rate. Thus, despite the national focus on mitigating disparities in health, this analysis shows that there has been no progress for the country as a whole and that Chicago is regressing.

Link and Phelan have clearly shown how it is possible (even inevitable) that general health could improve while disparities could worsen [21]. Indeed, in order to fight against such disparities, we will have to fight against both the fundamental causes like racism and poverty [21-23] as well as the derivative (or proximal or downstream) issues like segregation [24-27], inadequate housing [28], inadequate health care [29, 30], etc.

If racial disparities in health are to be eliminated, the fundamental causes must be addressed. While this process will no doubt take time, there are several steps that can be taken more immediately to work toward health equity. Examples of things that can be done before we are able to eliminate racism and poverty include determining where problem areas are and then developing and implementing appropriate health interventions in those areas [31, 32].

One way in which we can gain a better understanding of where our problem areas are is by performing analyses for geographic units below the national level (like the one presented in this paper). An examination of data below the national level can reveal which health conditions need to be addressed for specific localities since national averages mask local variation. This is clearly demonstrated in the present analysis where large differences are observed between the rates and disparities at the national level and those in Chicago. Similarly, we have performed analyses of diabetes and breast cancer mortality for the 50 largest US cities and found that mortality rates and disparities therein vary greatly across the USA [33, 34]. It is even possible (and encouraged) to take these analyses further and examine data for neighborhoods/ communities within cities. We have performed such analyses 
for Chicago for diabetes [35, 36] and stroke [37] mortality, as well as maternal smoking [38] and have found that rates vary tremendously across community areas within Chicago.

This type of data has allowed us to develop more targeted responses, focusing on areas we have determined to have higher rates of mortality. For example, as a result of these types of analyses, we have implemented Community Health Worker-based health interventions for diabetes, breast cancer, and pediatric asthma, targeting those Chicago communities which have been found to bear a disproportionate burden of these conditions. Additionally, data like these are key to catalyzing action. For example, in response to these data, the Metropolitan Breast Cancer Task Force was formed to eliminate disparities in breast health in Chicago [39, 40] and a community-based organization was developed to address the high rates of diabetes mortality in one Chicago community [41].

\section{Methodological Considerations}

Throughout this report, we have emphasized health disparities between Blacks and Whites and shown that these disparities are a major challenge facing the USA. However, we recognize that disparities likely exist among several other racial and ethnic groups, as well as between persons of differing SES, physical and mental abilities, sex, gender, etc. We consider this an important direction for future research.

It is also essential to point out that Black: White disparities can form and even increase while both rates improve, worsen, or move in opposite directions. Thus, for example, the Chicago disparity in heart disease mortality widened significantly over the 20 years despite the fact that both the Black and White rates improved substantially over the interval. The breast cancer mortality rate also widened $(p=0.10)$ and this occurred while the Black rate declined a little but the White rate declined dramatically. Most of the HSIs improved but this did not generally narrow disparities.

There are several ways to measure disparities [16, 42-45]. We have chosen to use the method of relative differences since it is consistent with our more recent previous report on this topic [9] which in turn was generated to be consistent with the paper generally regarded as the gold standard in this field [46].

\section{Conclusion}

In a paper about racial health disparities in Chicago that was published in 2001, we wrote: "Our analysis indicates that despite public health campaigns, general economic prosperity, and health advances, the health status of significant portions of the population, the black and the poor, in Chicago has gotten relatively worse compared to that of the white and wealthier populations. One thing is virtually certain: if we keep doing the same things we have been doing, we will be sitting here in 2010 wondering why the racial disparities in health are still increasing." [6, p. 493]. Well, we have analyzed the data for 2010 in this current report and are indeed still wondering why racial disparities in health in Chicago are still increasing. We hope this report will stimulate us to rethink our approaches and allow us to move forward on this most important front.

Conflict of Interest Author Bijou Hunt and Author Steve Whitman declare they have no conflict of interest.

Animal or Human Studies No animal or human studies were carried out by the authors for this article.

\section{References}

1. Dell J and Whitman S. A History of the Movement to Address Health Disparities. In Whitman, S. Shah, A. Benjamins, M. Urban Health: Combating Disparities with Local Data (8-30) Oxford University Press, 2010

2. Black \& Minority Health. Report of the Secretary's Task Force, Vol 1, Executive Summary. Washington DC: Department of Health and Human Services; 1985.

3. Healthy People 2000:National Health Promotion and Disease Prevention Objectives. Washington: DC: Department of Health and Human Services; 1991. DHHS publication PHS 91-50212.

4. Healthy People 2010. Understanding and improving health and objectives for improving health. Washington: Department of Health and Human Services; 2000.

5. Healthy People 2020. Healthy people in healthy communities. Washington: Department of Health and Human Services; 2010.

6. Silva A, Whitman S, Margellos H, Ansell D. Evaluating Chicago's success in reaching the healthy people 2000 goal of reducing health disparities. Public Health Rep. 2001;116(5):484-94.

7. Keppel KG, Pearcy JN, Wagener DK. Trends in racial and ethnicspecific rates for the health status indicators: United States, 1990-98. Healthy People 2000 Stat Notes. 2002; (23):1-16.

8. Margellos H, Silva A, Whitman S. Comparison of health status indicators in Chicago: are Black-White disparities worsening? Am J Public Health. 2004;94(1):116-21.

9. Orsi JM, Margellos-Anast H, Whitman S. Black-White health disparities in the United States and Chicago: a 15-year progress analysis. Am J Public Health. 2010;100(2):349-56.

10. Gamble VN and Stone D. U.S. Policy on Health Inequities: The interplay of Politics and Research. Journal of Health Politics, Policy and Law 31:93-126.

11. Anderson RN, Rosenberg HM. Age standardization of death rates: Implementation of the year 2000 standard. National vital statistics reports; 47(3). National Center for Health Statistics.: Hyattsville, Maryland; 1998.

12. Hoyert DL, Xu JQ. Deaths: Preliminary data for 2011. National vital statistics reports; vol 61 no 6. Hyattsville, MD: National Center for Health Statistics. 2012.

13. International Classification of Diseases. Ninth revision. Geneva: World Health Organization; 1980.

14. International Classification of Diseases. Tenth revision. Geneva: World Health Organization; 1992. 
15. Centers for Disease Control and Prevention. A guide to state implementation of ICD-10 for mortality part II: applying comparability ratios. Washington: National Center for Health Statistics; 2000.

16. These data were derived by the Chicago Department of Public Health from a record set supplied by the Illinois Department of Public Health (IDPH). IDPH specifically disclaims responsibility for any analysis, interpretations, or conclusions.

17. National Center for Health Statistics. Mortality - All County (microdata) (1990-2010), as compiled from data provided by the 57 vital statistics jurisdictions through the Vital Statistics Cooperative Program.

18. Keppel KG, Pearcy JN, Klein RJ. Measuring progress in Healthy People 2010. Healthy People 2010 Stat Notes. 2004;(25):1-16.

19. United Nations, Department of Economic and Social Affairs, Population Division (2013). World Population Prospects: The 2012 Revision, DVD Edition.

20. Satcher D, Fryer GE, McCann J, Troutman A, Woolf SH, Rust G. What if we were equal? A comparison of the black-white mortality gap in 1960 and 2000. Health Aff. 2005;24(2):459-64.

21. Phelan JC, Link BG. Controlling disease and creating disparities: a fundamental cause perspective. J Gerontol B Psychol Sci Soc Sci. 2005;60(Spec No. 2):27-33.

22. Isaacs SL, Schroeder SA. Class - the ignored determinant of the Nation's health. N Engl J Med. 2004;351(11):1137-42.

23. Smedley BD. Expanding the frame of understanding health disparities: from a focus on health systems to social and economic systems. Health Educ Behav. 2006;33(4):538-41.

24. Massey D, Denton N. American apartheid: segregation and the making of the underclass. Cambridge: Harvard University Press; 1993.

25. Collins C, Williams DR. Segregation and mortality: the deadly effects of racism? Sociol Forum. 1999;14(3):495-523.

26. Krieger N, Sidney S. Racial discrimination and blood pressure: the CARDIA study of young Black and White adults. Am J Public Health. 1996;86(10):1370-8.

27. Cooper RS, Kennelly JF, Durazo-Arvizu R, Oh HJ, Kaplan G, Lynch J. Relationship between premature mortality and socioeconomic factors in black and white p9opulations of US metropolitan areas. Public Health Rep. 2001;116(5):464-73.

28. Williams DR, Collins C. Racial residential segregation: a fundamental cause of racial disparities in health. Public Health Rep. 2001;116(5):404-16.

29. Smedley B, Stith A, Nelson A, editors. Unequal treatment: confronting racial and ethnic disparities in health care. Washington: The National Academies Press; 2002.

30. Epstein AM, Ayanian JZ. Racial disparities in medical care. N Engl J Med. 2001;344(19):1471-3.

31. Whitman S, Shah AM, Benjamins MR, editors. Urban health: combating disparities with local data. New York: Oxford University Press; 2010.
32. Centers for Disease Control and Prevention. CDC Reports on Effective Strategies for Reducing Health Disparities. Washington, D.C. National Center for Health Statistics; 2014. Available at: http:// www.cdc.gov/media/releases/2014/p0417-health-disparities.html. Accessed July 23, 2014.

33. Rosenstock S, Whitman S, West JF, Balkin M. Racial disparities in diabetes mortality in the 50 most populous US cities. J Urban Health. 2014. doi:10.1007/s11524-013-9861-4.

34. Hunt BR, Whitman S, Hurlbert M. Increasing Black:White disparities in breast cancer mortality in the 50 largest cities in the United States. Cancer Epidemiol. 2013. doi:10.1016/j.canep.2013.09.009.

35. Whitman S, Silva A, Shah AM. Disproportionate impact of diabetes in a Puerto Rican community of Chicago. J Community Health. 2006;31(6):521-31.

36. Hunt B, Whitman S, Henry C. Age-adjusted diabetes mortality rates vary in local communities in a metropolitan area: racial and spatial disparities and correlates. Diabetes Care. 2014. doi:10.2337/dc130988.

37. Hunt BR, Deot D, Whitman S. Stroke mortality rates vary in local communities in a metropolitan area: racial and spatial disparities and correlates. Stroke. 2014. doi:10.1161/STROKEAHA.114.005431.

38. Hunt BR, Whitman S. Maternal smoking in Chicago: a communitylevel analysis. J Health Care Poor Underserved. 2011;22:194-210.

39. Chicago Metropolitan Breast Cancer Task Force. Improving Quality and Reducing Disparities in Breast Cancer Mortality in Metropolitan Chicago. October 2007. Available at: http://www.suhichicago.org/ files/publications/Task\%20Force\%20Rpt_Oct\%202007_FINAL. pdf. Accessed March 25, 2014.

40. Chicago Metropolitan Breast Cancer Task Force Website. Available at: http://www.chicagobreastcancer.org/. Accessed March 25, 2014.

41. Whitman S, López JE, Rothschild SK, and J Delgado. Disproportionate Impact of Diabetes in a Puerto Rican Community of Chicago. In Whitman, S. Shah, A. Benjamins, M. Urban Health: Combating Disparities with Local Data (225-246). Oxford University Press, 2010.

42. Pearcy JN, Keppel KG. A summary measure of health disparity. Public Health Rep. 2002;117(3):273-80.

43. Keppel KG, Pamuk E, Lynch J, et al. Methodological issues in measuring health disparities. Vital Health Stat. 2005;2(141):1-16.

44. Drewette-Card RJ, Landed MG. The disparity change score: a new methodology to examine health disparities in New Mexico. J Public Health Manag Pract. 2005;11(6):484-92.

45. Krieger N, Chen JT, Waterman PD, Rehkopf DH, Subramanian SV. Paining a truer picture of US socioeconomic and racial/ethnic health inequalities: the Public Health Disparities Geocoding Project. Am J Public Health. 2005;95(2):312-23.

46. Keppel KG. Ten largest racial and ethnic health disparities in the United States based on healthy people 2010 objectives. Am J Epidemiol. 2007;166(1):97-103. 